\title{
Trombositoz saptanan çocuklarda klinik ve hematolojik profilin değerlendirilmesi
}

\section{Evaluation of clinic and hematological profile of children with thrombocytosis}

\author{
Melahat Melek OĞUZ*司, Esma Altınel AÇOĞLUロ
}

Sağlık Bilimleri Üniversitesi, Dr Sami Ulus Kadın Doğum Çocuk Sağlı̆̆ı ve Hastalıkları Hastanesi, Pediatri Kliniği, Ankara/TÜRKiYE

\section{öz}

Amaç: Trombositoz çocuklarda beklenmeyen bir bulgu olarak karşımıza çıkmakta ve daha çok reaktif trombositoz görülmektedir.Bu çalışmanın amacı çocuklarda trombositozun; sıklığııı, nedenlerini, düzelme süresini, trombosit parametreleri ve enfeksiyon belirteçleri ile korelasyonunu belirlemektir.

Gereç ve Yöntemler: Ekim 2016 ile Mayıs 2018 tarihleri arasında Dr. Sami Ulus Kadın Doğum ve Çocuk Sağlığı ve Hastalıkları Eğitim ve Araştırma Hastanesinde 6 ay 18 yaş arası trombositoz saptanan çocukların dahil edildiği tanımlayııı bir çalışmadır.

Bulgular: Toplam 107564 hastanın \%10,8 ( $\mathrm{n}=11643$ )'inde trombositoz saptandı. Bu hastaların \%64,5'i 6ay-2 yaş arası çocuklardan oluşuyordu. Ciddi trombositozun $141(\% 1,2)$ hastada geliştiği görüldü.En sık ciddi trombositoz nedenleri sırası ile 80 hastada $(\% 56,8)$ enfeksiyonlar, 21 hastada anemi $(\% 14,9), 14(\% 9,9)$ hastada ise otoimmun hastalıklar idi. Ciddi trombositozların ortalama düzelme süresi 40,2 234 gün (3-210) olarak hesaplandı. Hastaların hiçbirinde tromboembolik komplikasyon görülmedi. Trombosit sayısı ile ortalama trombosit hacmi arasında istatistiksel olarak anlamlı negatif korelasyon olduğu görüldü $(p<0,05, r=-0,214)$. Trombosit dağılım genişliği düzeyi ile trombosit sayısı arasında korelasyon görülmedi $(p=0,95)$. CRP düzeyi ile trombosit sayısı arasında istatistiksel olarak anlamlı korelasyon saptanmadı $(p=0,15)$. Trombosit sayısı ile sedimantasyon hızı arasında ise istatistiksel olarak anlamlı korelasyon bulundu $(p<0,05, r=0,233)$.

Sonuç: Çalışmamızda reaktif trombositozun sık rastlanılan bir bulgu olduğunu ve bu büyük örneklemde primer trombositozun hiç görülmediğini, sekonder trombositozda altta yatan birçok farklı nedenin olabileceğini saptadık. Dolayısı ile trombositozun ayırıcı tanısı ve yaklaşımı pediatri uzmanı tarafından yapılmalıdır ve hematoloji bölümü konsültasyonu nadiren gerekmektedir. Özellikle ciddi trombositozlarda gösterebildiğimiz enfeksiyon veya anemi yoksa kronik inflamatuar hastalıkların altta yatan neden olabileceği unutulmamalıdır.

Anahtar Kelimeler: trombositoz; primer etyoloji; sekonder etyoloji

Sorumlu Yazar*: Melahat Melek Oğuz, Sağlık Bilimleri Üniversitesi, Dr Sami Ulus Kadın Doğum Çocuk Sağlığı ve Hastalıkları Hastanesi, Pediatri Kliniği, Ankara/TÜRKiYE

E-posta: melekboynukalin@gmail.com

ORCID: 0000-0002-4149-4469

Gönderim: 17.07.2018 kabul: 06.08.2018

Doi: $10.18663 /$ tjcl.444674 


\section{ABSTRACT}

Aim: Thrombocytosis is come across as an unexpected finding in children and usually appears as reactive thrombocytosis. The objective of this study is to determine the incidence rate of thrombocytosis in children, the etiologic factors, duration until normalization of thrombocytosis and the correlation between thrombocytosis and thrombocyte parameters and other variables.

Material and Methods: The study included the children between 6 months and 18 years of age who were admitted to Dr. Sami Ulus Maternity and Children's Health and Diseases Training and Research Hospital and were diagnosed as thrombocytosis.

Results: The incidence of thrombocytosis was found to be $10.8 \%$ among 107564 pediatric patients throughout two years period. Sixty four point five percent of these patients were the children between ages of 6 months and 2 years. Severe thrombocytosis developed in $141(1.2 \%)$ patients. The most common acute thrombocytosis causes were, infection in 80 patients (56.8\%), anemia in 21 patients (14.9\%), autoimmune diseases in 14 patients (9.9\%) respectively. The average normalization of acute thrombocytosis was $40.2 \pm 34$ days (3-210). No thromboembolic events were observed. There was a significant negative correlation between the platelet number and the MPV $(p<0.05, r=-0.214)$. No correlation was found between platelet numbers and PDW levels $(p=0.95)$. Statistically significant correlation was found between the number of platelet and the sedimentation rate $(p<0.05, r=0,233)$ while no correlation was found between CRP level and thrombocyte number $(p=0.15)$.

Conclusions: The study showed that reactive thrombocytosis is a common finding which implies varying underlying reasons. In our sample of patients primary thrombocytosis was never observed. For this reason the differential diagnosis and treatment of thrombocytosis can be evaluated by basic pediatric approach and hematology consultation is rarely needed. Especially in acute thrombocytosis if there is no observable infection or anemia the underlying causes can be the chronic inflammatory diseases.

Key words: thrombocytosis; primary etiology; secondary etiology

\section{Giriş}

Sağlıklı çocuklarda normal trombosit sayısı 150000-450000/ $\mu \mathrm{L}$ olarak kabul edilmektedir. Trombosit sayısının +2 standart deviasyon skorunun (SDS)üzerine çıkması trombositoz olarak değerlendirilir.Trombositoz; trombosit sayısı 450000-700000 / $\mu \mathrm{L}$ arasında ise hafif, $700000-900000 / \mu \mathrm{L}$ arası orta, $>900000 /$ $\mu \mathrm{L}$ ciddi olarak tanımlanmaktadır. Aynı zamanda trombositoz saptanan hastaları nedene göre primer ve sekonder olarak da sınıflandırmak mümkündür[1]. Primer(esansiyel) trombositoz, hematopoetik hücrelerin kontrolsüz çoğalmasına bağlı oluşan miyeloproliferatif bir bozukluktur. Sekonder trombositoz ise enfeksiyon, inflamasyon, demir eksikliği anemisi, malignensi gibi altta yatan birçok nedene bağlı olarak görülmektedir. Primer-sekonder ayrımını yapmak bazen güç olabilir. Klinikte trombositoz beklenmeyen ancak sık bir bulgu olarak karşımıza çıkmaktadır. Trombositozun nedenini saptamak için bazen ayrıntılı incelemelere gerek duyulmaktadır. Bu çalışmanın amacı çocuklarda trombositozun; sıklı̆ı̆ıı, nedenlerini, düzelme süresini, trombosit parametreleri ve enfeksiyon belirteçleri ile korelasyonunu belirlemek ve trombositoz için farkındalık oluşturmaktır.

\section{Gereç ve Yöntemler}

Bu çalışma Ekim 2016 ile Mayıs 2018 tarihleri arasında Dr. Sami Ulus Kadın Doğum ve Çocuk Sağlığı ve Hastalıkları Eğitim ve Araştırma Hastanesinderetrospektif olarak yapıldı. Yaşı altı ay ve üstü olup hastanemize çeşitli nedenlerle başvuran ve tam kan sayımı yapılan çocuklardan trombositoz (trombosit sayısı $>450 \times 103 / \mu \mathrm{L})$ saptananlar çalışmaya dahiledildi. Çocukların yaşları, cinsiyetleri, hemoglobin $(\mathrm{Hb})$, ortalama eritrosit hacmi (MCV), eritrosit dağılım genişliği (RDW), beyaz küre sayısı (WBC), ortalama trombosit hacmi (MPV)[6,8-9,7fL], trombosit dağılım genişliği (PDW) [\%44-56], C-reaktif protein (CRP) $[0-4 \mathrm{mg} / \mathrm{L}]$, sedimantasyon $[0-20 \mathrm{~mm} / \mathrm{saat}]$ değerleri kaydedildi. Ağır trombositoz saptanan hastaların hastaneye başvuru şikâyetleri, kullanmakta olduğu ilaçlar, splenektomi hikayesi ve trombositozun ne kadar sürede düzeldiği kaydedildi. Trombositoz sınıflaması aşağıdaki gibi yapıldı.
1) Hafif trombositoz $(450 \times 103 / \mu \mathrm{L}-700 \times 103 / \mu \mathrm{L})$
2) Orta trombositoz $(700 \times 103 / \mu \mathrm{L}-900 \times 103 / \mu \mathrm{L})$
3) Ciddi trombositoz ( $900 \times 103 / \mu \mathrm{L}$ ve üstü)

Trombositoz etiyolojisi klinik ve laboratuvar veriler hasta dosyaları incelenerek elde belirlendi. 
Çalışma için lokal etik kuruldanonay alındı. Çalışma Helsinki İlkeler Deklerasyonuna uyularak gerçekleştirilmiştir.

Veriler SPSS 15 paket programı kullanılarak analiz edildi. Tanımlayıcı istatistikler; sürekli değişkenler için \pm standart sapma, kategorik değişkenler için ise sayı ve yüzde olarak ifade edildi. İstatistik hesaplamalarda anlamlılık (önemlilik) düzeyi \%5 olarak alındı. Ortalamaların ve yüzdelerin gruplar arası karşılaştırılmasında ANOVA testi kullanıldı.Korelasyon analizlerinde pearson korelasyon (r) katsayısı kullanıldı. Çalışma için yerel etik kurul onayı alındı. Hasta onam formları imzalatıldı.

\section{Bulgular}

Ekim 2016 ile Mayıs 2018 tarihleri arasında Dr. Sami Ulus Kadın Doğum ve Çocuk Sağlığı ve Hastalıkları Eğitim ve Araştırma Hastanesinde 6 ay-18 yaş arası çocuklarda bakılan toplam hemogram sayısı 152179 idi. Hemogram bakılan toplam hasta sayısı ise 107564 olarak bulundu. Hemogram bakılan hastaların $\% 10,8$ (n:11643)'inde trombositoz saptandı. Trombositoz saptanan hastaların \%56,7'sini erkekleroluşturuyordu, yaş ortalaması 36,9 $\pm 44,2$ (6-216 ay) idi. Çalışmaya dahil edilen çocukların \%64,5 ( $n=7512)$ 'i 6ay-2 yaş arasında, \%19,3(2246)'ü 2-5 yaş arası çocuklar oluşturuyordu. Hastaların \%92,4'ünü ( $n=10765)$ hafif trombositozlu olgular, $\% 6,3$ ( $n=737$ )'ünü orta derecede trombositozu olanlar, \%1,2 ( $n=141)$ 'sini ise ağır trombositozu olan hastalar oluşturuyordu (Tablo1).

\begin{tabular}{|c|c|c|c|c|}
\hline \multicolumn{5}{|c|}{$\begin{array}{l}\text { Tablo1: Trombositoz saptanan hastaların yaşa ve trombosi- } \\
\text { toz derecesine göre dağılımı }\end{array}$} \\
\hline Trombositoz & 6ay-2 yaş & $2-5$ yaş & 5 yaş< & Toplam \\
\hline HafifTrombositoz & 6948 & 2061 & 1756 & $10765(\% 92,5)$ \\
\hline Orta Trombositoz & 473 & 158 & 106 & $737(\% 63,3)$ \\
\hline Ağır Trombositoz & 91 & 27 & 23 & $141(\% 12,2)$ \\
\hline Toplam & $\begin{array}{l}7512 \\
(\% 64.5)\end{array}$ & $\begin{array}{l}2246 \\
(\% 19,3)\end{array}$ & $\begin{array}{l}1885 \\
(\% 16,2)\end{array}$ & $11643(\% 100)$ \\
\hline
\end{tabular}

Ağır trombositoz nedenlerine bakıldığında sırası ile 80 hastada $(\% 56,8)$ enfeksiyonlar, 21 hastada anemi $(\% 14,9), 14(\% 9,9)$ hastada ise otoimmun (kronik inflamatuar) hastalıklar olarak saptandı (Tablo 2). Sekiz $(\% 5,7)$ hastada ise herhangi bir neden bulunamadı. En sık enfeksiyöz hastalıklar alt solunum yolu enfeksiyonları $(\% 55,3)$, akut gastroenteritler $(\% 15,8)$ ve idrar yolu enfeksiyonları $(\% 11,8)$ idi. Trombositoza neden olan otoimmun hastalıklar sırası ile 8 hastada Kawasaki Hastalığı, 4 hastada Henoch Schönlein Purpurası, 1 hastada inflamatuar bağırsak hastalığı (iBH), 1 hastada ise akut romatizmal ateş idi. Sekiz hastada malignite saptandı; bunların 6'sında enfeksiyona bağlı trombositoz, 2'sinde ise ilaca (filgrastim, deksametazon) bağlı trombositoz geliştiği görüldü.lki hastada perfore appandisite bağı trombositoz görüldü. 1 hastada anemi ile birlikte raşitizim vardı. Anemi saptanan 32 hastanın 28'inde demir eksikliği anemisi saptanırken diğer 4 hastada sırası ile herediter sferositoz(splenektomi ile birlikte $(n=2))$, talasemi intermedia $(n=1)$, otoimmun hemolitik anemi $(n=1)$ olduğu belirlendi. Çalışmamızda primer trombositoz görülmedi. Hiçbir hastada trombotik komplikasyon görülmedi.

\begin{tabular}{lll}
\hline \multicolumn{2}{l}{ Tablo 2: Ciddi Trombositoz Nedenleri } & \\
\hline & \multicolumn{1}{l}{ Sayı=141 } & Yüzde:100 \\
\hline II) PrimerTrombositoz & 0 & $\% 0$ \\
II)ReaktifTrombositozis & 141 & $\% 100$ \\
Enfeksiyon & 80 & $\% 56,8$ \\
Anemi & 21 & $\% 14,9$ \\
Anemi+ Enfeksiyon & 11 & $\% 7,8$ \\
Kawasaki & 8 & $\% 5,7$ \\
HenochSchönleinPurpurası (HSP) & 4 & $\% 2,8$ \\
Konjenital Kalp Hastalı̆ı & 2 & $\% 1,4$ \\
Ilaca bağlı & 2 & $\% 1,4$ \\
Perfore appandisit & 2 & $\% 1,4$ \\
İnflamatuar bağırsak hastalı̆̆ı & 1 & $\% 0,7$ \\
Akut Romatizmal Ateş & 1 & $\% 0,7$ \\
İdiopatik & 9 & $\% 6,4$
\end{tabular}

Hastaların başvuru şikayetlerigözden geçirildiğinde $\% 48,2$ $(n=63)$ 'sinin ateş şikayeti ile \%33,3 ( $n=47)$ 'nün solunum sistemi semptomları, \%12,1 ( $n=17)$ 'ningastrointestinal semptomlar ile $\% 1,4$ ( $n=2$ )'ünün ise hiçbir şikayet yokken başvurduğu tespit edildi. Şikayeti olmayan bu iki hastada demir eksikliği anemisi saptandı.

Ciddi trombositozların ortalama düzelme süresi 40,2 \pm 34 gün(3-210 gün) olarak hesaplandı. Ciddi trombositozların $\% 64,5^{\prime} \mathrm{i}$ ( $\mathrm{n}=91$ ) hastanede yatan hastalardan oluşuyordu. Hastanede yatışı sırasında trombositoz saptanan hastaların hepsine intravenöz hidrasyon başlandığı tespit edildi.Dokuz hastaya aspirin başlandı;bunların 8 tanesi Kawasaki Hastalığı tanısı almıştı, 1 tanesi ise ARA nedeni ile takipli idi.

Tüm gruplarda trombosit parametrelerine bakıldığında MPV ortalama değeri hafif trombositoz grubunda $7,56 \mathrm{fL}$, orta derece trombositoz saptanan grupta 7,41fL, ciddi trombositoz olan grupta ise 7,35fL bulundu. Trombosit sayısı ile MPV arasında istatistiksel olarak anlamlı negatif korelasyon olduğu görüldü $(p<0,05, \quad r=-0,214)$. Gruplar arası ortalama PDW düzeyleri arasında istatistiksel olarak anlamlı fark saptanmadı $(p=0,35)$. PDW düzeyi ile trombosit sayısı arasında korelasyon da görülmedi $(p=0,95)$. CRP düzeyi ile trombositoz sayısı arasında korelasyon saptanmazken $(p=0,15)$, trombosit sayısı ile sedimantasyon arasında ise istatistiksel olarak anlamlı korelasyon bulundu ( $p<0,05, r=0,233)$ (Tablo 3 ). 


\begin{tabular}{|c|c|c|c|c|}
\hline & Hafif Trombositoz & OrtaTrombositoz & CiddiTrombositoz & $\begin{array}{l}r \text { değeri } \\
\text { ( } p \text { değeri) }\end{array}$ \\
\hline Ortalama MPV (fL) & $7,56 \pm 0,81$ & $7,41 \pm 0,79$ & $7,35 \pm 0,78$ & $\begin{array}{l}-0,214 \\
(<0,05)\end{array}$ \\
\hline Ortalama PDW (\%) & $39,5 \pm 0,68$ & $41,3 \pm 0,72$ & $37,6 \pm 0,71$ & $\begin{array}{l}-0,051 \\
(0,95)\end{array}$ \\
\hline OrtalamaCRP (mg/L) & $48,4 \pm 10,9$ & $42,5 \pm 11,3$ & $49,4 \pm 11,6$ & $\begin{array}{l}0,562 \\
(0,15)\end{array}$ \\
\hline Ortalama Sedimantasyon hızı (mm/saat) & $18,6 \pm 5,6$ & $28,3 \pm 3,2$ & $64,7 \pm 5,9$ & $\begin{array}{c}0,233 \\
(<0,05)\end{array}$ \\
\hline
\end{tabular}

\section{Tartışma}

Trombositoz çocuklarda sık rastlanan ancak yeterince araştırılmamışbir bulgudur. Bunun nedeni nadiren semptoma yol açması ve çoğunlukla akut faz reaksiyonu olarak görülmesidir[2]. Üçüncübasamak çocuk hastanesinde retrospektif olarak yaptığımız bu çalışmada trombositoz insidansı\%10,8 olarak bulundu.Literatürde çocuklarda sekondertrombositozsıklığıileilgiliyapılmışçalışmalarda\%6-15 arası değişen sonuçlar verilmiştir. Ancak bu çalışma yatan hastalarda yapılmıştır[3]. Çalışmamızda trombositozların sadece \% 12,2'sinde ciddi trombositoz saptanırken etiyolojide $\% 56,8$ oranında enfeksiyonlar ilk sırada yer almaktaydı. Enfeksiyon hastalıklarını anemi ve otoimmun hastalıklar takip etti.Erişkin çalışmalarında primer trombositoza çok daha sık rastlanırken çocuklarda daha çok ikincil nedenlere bağı reaktif trombositoz görülmektedir.Reaktif trombositozda mekanizma altta yatan nedene göre değişkenlik göstermektedir. Megakaryosit proliferasyonu, trombosit salınımının artması ve/veya trombosit sekestrasyonunun veya döngüsünün azalması patofizyolojide rol oynamaktadır. Primer trombositoz megakaryosit öncüllerinin spontan olarak üretimindeki ve trombopoetine (Tpo) duyarlılıklarındaki artışa bağlı gelişmektedir. Sekonde rtrombositoz ise akut faz cevabı olarak hepatik Tpo sentezindeki artışa bağlı olarak megakaryosit öncüllerini uyarılması ile gelişmektedir[4]. Literatürde esansiyel trombositoz insidansı 100000 'de $0,6-2,5$ olarak bildirilmiştir[5]. Onbir bin altıyüz kırk üç (11643) trombositoz saptanan hastanın tarandığı çalışmamızda esansiyel trombositoz görülmedi. Sekonder trombositoza 2 yaş altında daha sık rastlanılmaktadır[6]. Benzer olarak çalışmamızda da trombositozların $\% 64,5^{\prime} \mathrm{i} 2$ yaş altındaki çocuklarda görüldü.

Çalışmalarda çocuklarda sekonder trombositozların en sık nedeni olarak enfeksiyonlar bildirilmiş olup bizim çalışmamızda da aynı sonuca ulaşılmıştır. Solunum yolu enfeksiyonlarında trombositoza sık rastlanırken literatürde gastrointestinal ve üriner sistem enfeksiyonları da dikkat çekicidir [7].
Trombosit sayısı, inflamatuar bağırsak hastalığı, Kawasaki gibi kronik inflamasyonla giden hastalıklarda yükselmektedir. Çalışmamızda da ciddi trombositoz olan grupta, 8 hastada Kawasaki, 1 hastada inflamatuar bağırsak hastalığı, 1 hastada ise akut romatizmal ateş tanısı olduğu görüldü. Kronik inflamatuar hastalıklarda, inflamatuar mediatörlerin salıımına bağlı olarak kemik iliğinde trombosit yapımı uyarılmakta ve trombosit ömrü uzamaktadır[8]. Kronik inflamatuar hastalıklardan Kawasaki Hastalığı çocukluk çağının göreceli olarak daha sık rastlanan vaskülitidir. Özellikle infantlarda klinik bulguların daha silik olması nedeni ile tanı koymada zorluk yaşanmaktadır. Lise ve arkadaşlarının yaptıkları çalışmada ciddi trombositoz saptanan hastalarda Kawasaki Hastalığı olma ihtimalinin 17 kat arttığı tespit edilmiştir[9]. Kawasaki Hastalığı́nın çocuklarda görülme sıklığı yüzbinde 8,9 olarak bildirilmektedir[10]. Bizim çalışmamızda ciddi trombositozu olan grupta Kawasaki hastalığı sıklığı \%5,7 olarak bulundu.Benzer şekilde kronik inflamatuar bir hastalık olan IBH'da yapılan çalışmalar trombositozun hastalık aktivitesi ve demir eksikliği anemisi ile belirgin korelasyonu olduğunu göstermiştir. Hastaların takibinde trombosit sayısının artışının diğer akut faz reaktanlarına göre daha anlamlı olduğu görülmüştür[ $[8,11]$. Çalışmamızda ciddi trombositoz saptanan hastalardan dördünde Henoch Schönlein Purpurası (HSP) olduğu belirlendi. Yine hastalığın ciddiyeti ile orantılı şekilde HSP tanısı alan hastalarının yaklaşık \%60-70'inde trombositoz saptanmaktadır bu da trombopoetinden ziyade IL-6 ilişkili kronik inflamasyona bağlanmıştır[12]. Kronik inflamasyon göstergesi olan sedimantasyon değerinin çalışmamızda trombosit sayısı ile anlamlı korelasyon gösterdiğini saptadık. Ancak trombosit sayısı ile CRP arasında istatistiksel olarak anlamlı korelasyon saptanmadı. Griesshammer ve arkadaşlarının yaptıkları çalışmada sedimantasyonun sekonder trombositozu olan olgularda primer trombositozlara göre anlamlı olarak daha yüksek olduğu gösterilmiştir[13]. 
Çalışmamızda 2 hastada ilaca bağlı trombositoz görüldü. Vakalardan bir tanesi Burkitt lenfoma nedeniyle deksametazon tedavisi alırken,diğeri ise non-hodgkin lenfoma kemoterapi tedavisi sonrası filgrastim(granulocyte colony stimulating factor-GCSF) tedavisinin 2. gününde trombositoz geliştirmişti. Literatürde GCSF'e bağlı ciddi trombositoz çok nadir bildirilmiştir ve megakaryosit yüzeyinde eksprese edilen GCSF reseptörüne bağlı olarak geliştiği düşünülmektedir[14]. Kortikosteroidlerin ise dalakta depolanmış trombositlerin dolaşıma salınmasına yol açarak geçici trombositoz yaptığı bilinmektedir[4].

Demir eksikliği anemisi klinik tecrübe ve literatürde yapılmış çalışmalar eritropoetik ve trombotik büyüme faktörleri arasındaki ilişki sonucu trombosit üretimindeki artışa bağlı olarak artmaktadır. Bir başka mekanizmada ise demir eksikliğinde trombositlerdeki tübülin sentezinin azalmasına bağlı kompanzatuar trombosit yapımının arttığı düşünülmektedir[15]. Çalışmamızda enfeksiyondan sonra en sık görülen trombositoz nedeni demir eksikliği anemisi olarak bulundu. Bir hasta da talasemi intermedia nedeniyle takipli idi. Benzer çalışmalarda da anemi trombositoza sık neden olan bir durum olarak tespit edilmiştir[16].. Iki hasta ise herediter sferositoz nedeniyle splenektomi olmuştu ve splenektomi sonrası bu hastalarda trombositoz gelişmiş̧ti. Splenektomi sonrası görülen reaktif trombositoz sıklığı \%75-82 olarak bildirilmektedir ve 280 vakalık erişkinlerde yapılmış bir çalışmada trombositoz yapan nedenler içinde splenektomi\%19oranında bildirilmiştir. Çocuklarda ise daha nadirdir.Trombositregülasyonunda önemli rol oynayan dalağın alınması ile 1-3 hafta içerisinde trombositoz gelişmektedir. Trombosit sayısının normale dönmesi haftalar veya aylar içinde olmakta nadiren de yıllarca sürebilmektedir[17].

Trombositozda tedaviyi belirlemede en önemli soru trombositozun primer mi sekonder mi olduğudur. Reaktif trombositozdat rombosit sayısının düşürülmesine veya antitrombosit tedavisinin verilmesine gerek yoktur. Anormal trombosit sayısı kendi başına hastayı hemostatik ve vasküler olaylar için riske sokmaz. Sekonder trombositozda altta yatan hastalığın tedavisini yapmak yeterlidir.Trombosit sayısını azaltmaya çalışmak gibi bir amacımız olmamalıdır. Hidrasyon, aspirin ve diğer ajanlar sekonder trombositozda önerilmez. Çocuklarda tedavi sadece esansiyel trombositozlarda ve tromboembolik komplikasyonlarda kullanılmalıdır. Ayrıca esansiyel trombositozda bile erişkinlere göre çocuklardaki tedavide daha konservatif yaklaşım önerilmektedir[18,19]. Çalışmamızda Kawasaki Hastalığı ve ARA nedeniyle takipli toplam 9 hastaya doğru endikasyonla aspirin tedavisi verildiği görüldü. Ciddi trombositozu olan hastaların ise \%64,5'ine literatürde önerilmediği halde intravenöz hidrasyon yapıldığı tespit edildi. Ciddi trombositozun düzelme süresini ortalama

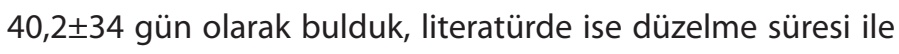
ilgili nadir çalışmaya rastladık ve düzelme zamanı ile ilgili farklı sonuçlara rastladık. Rowa ve arkadaşlarının 36 tane sekonder trombositoz saptanan hastada yaptıkları çalışmada sadece 21 hasta takibe alınabildiği ve bu hastaların hepsinin trombosit sayısının üçüncü ayın sonunda düzeldiği ve ortanca düzelme süresinin ise 4 hafta olduğu belirtilmiştir. Chan ve arkadaşları ise trombositozun ikinci günden sonra düzelmeye başladığını bildirmiştir[20,21].Trombositozun düzelme süresi ile ilgili bu farklılığın nedeni trombosit ömrü, inflamasyonun geçiş süresi ve altta yatan hastalığın iyileşme zamanından kaynaklı olabilir. Bu çalışmada artan trombosit sayısı ile MPV değeri arasında negatif istatistiksel olarak anlamlı korelasyon saptanırken PDW değeri ile trombositoz ciddiyeti arasında anlamlı korelasyon görülmedi. Literatürdeki benzer çalışmalarda da aralarında negatif korelasyon olduğu gösterilmiştir[22]. Çünkü MPV değerinin düşük olması trombosit fonksiyonu ve aktivasyonu için bir gösterge olarak bilinmektedir[23].

\section{Sonuç}

Çalışmamızda reaktif trombositozun sık rastlanılan bir bulgu olduğunu ve bu büyük örneklemde primer trombositozun hiç görülmediğini, sekonder trombositozdaaltta yatan birçok farklı nedenin olabileceğini saptadık. Trombositozun ayırıcı tanısı ve yaklaşımı pediatri uzmanı tarafından yapılmalıdır. Çalışmamızın da trombositoz konusunda farkındalık oluşturacağını düşünüyoruz. Özellikle ciddi trombositozlarda gösterebildiğimiz enfeksiyon veya anemi yoksa kronik inflamatuar hastalıkların altta yatan neden olabileceği unutulmamalıdır.

\section{Çıkar çatışması / finansal destek beyanı}

Bu yazıdaki hiçbir yazarın herhangi bir çıkar çatışması yoktur. Yazının herhangi bir finansal desteği yoktur

\section{Kaynaklar}

1. Chiarello P, Magnolia M, Rubino M, Liguori S, Miniero R. Thrombocytosis in children. Minerva pediatrica 2011; 63: 507-13.

2. Harrison $\mathrm{CN}$, Bareford D, Butt $\mathrm{N}$ et al. Guideline for investigation and management of adults and children presenting with a thrombocytosis. British journal of haematology 2010; 149: 352-75.

3. Dame C, Sutor AH. Primary and secondary thrombocytosis in childhood. British journal of haematology 2005; 129: 165-77. 
4. Kucine N, Chastain KM, Mahler MB, Bussel JB. Primary thrombocytosis in children. Haematologica 2014; 99: 620-28.

5. Aladily TN, Mohammad RS, Al-Khader A, Awidi AS. Essential Thrombocythemia in a Two-year-old Child, Responsive to Hydroxyurea but Not Aspirin. Oman medical journal 2017; 32: 243.

6. Indolfi G, Catania P, Bartolini E et al. Incidence and clinical significance of reactive thrombocytosis in children aged 1 to 24 months, hospitalized for community-acquired infections. Platelets 2008; 19: 409-14.

7. Zheng S-Y, Xiao Q-Y, Xie X-H et al. Association between secondary thrombocytosis and viral respiratory tract infections in children. Scientific reports 2016; 6: 22964.

8. Matowicka-Karna J. Markers of inflammation, activation of blood platelets and coagulation disorders in inflammatory bowel diseases. Postepy higieny i medycyny doswiadczalnej (Online) 2016; 70: 305-12.

9. Nigrovic LE, Nigrovic PA, Harper MB, Chiang VW. Extreme thrombocytosis predicts Kawasaki disease in infants. Clinical pediatrics 2006; 45: 446-52.

10. Özdemir H, Çiftçi E, Tapısız A et al. Clinical and epidemiological characteristics of children with Kawasaki disease in Turkey. Journal of tropical pediatrics 2009; 56: 260-62.

11. Voudoukis E, Karmiris K, Koutroubakis IE. Multipotent role of platelets in inflammatory bowel diseases: a clinical approach. World Journal of Gastroenterology: WJG 2014; 20: 3180.

12. Lin C, Yang Y, Lee C, Huang C, Wang L, Chiang B. Thrombopoietin and interleukin- 6 levels in Henoch-Schonlein purpura. Journal of Microbiology Immunology and Infection 2006; 39: 476.

13. Griesshammer M, Bangerter M, SauerT, Wennauer R, Bergmann L, Heimpel H. Aetiology and clinical significance of thrombocytosis: analysis of 732 patients with an elevated platelet count. Journal of internal medicine 1999; 245: 295-300.
14. Dihingia S, Deka K, Bhuyan D, Mondal SK. Life-threatening thrombocytosis following GCSF treatment in a case of clozapineinduced agranulocytosis. General hospital psychiatry 2012; 34: 320.

15. Yung KC, Zhang ZW, Yu WJ et al. Preliminary investigation about the expression of tubulin in platelets from patients with iron deficiency anemia and thrombocytosis. Hematology 2018; 23: 549-57.

16. Subramaniam N, Mundkur S, Kini P, Bhaskaranand N, Aroor S. Clinicohematological study of thrombocytosis in children. ISRN hematology 2014; 2014: 389257.

17. Khan PN, Nair RJ, Olivares J, Tingle LE, Li Z. Postsplenectomy reactive thrombocytosis. Baylor University Medical Center Proceedings; 2009: Taylor \& Francis.

18. Kiro K, Ganjoo P, Saigal D, Hansda U. Incidental thrombocytosis: Should it concern the anesthesiologist? Journal of anaesthesiology, clinical pharmacology 2014; 30: 281.

19. Mantadakis E, Tsalkidis A, Chatzimichael A. Thrombocytosis in childhood. Indian pediatrics 2008; 45: 669.

20. Vora A, Lilleyman J. Secondary thrombocytosis. Archives of disease in childhood 1993; 68: 88-90.

21. Chan KW, Kaikov Y, Wadsworth LD. Thrombocytosis in childhood: a survey of 94 patients. Pediatrics 1989; 84: 1064-67.

22. Sarangi R, Pradhan S, Dhanawat A, Patanayak R, Benia G. Thrombocytosis in children: Clinico-hematological profile from a single centre in Eastern India. Journal of laboratory physicians 2018; 10: 34

23. Gokcek E, Kaydu A. Investigation of mean platelet volume and platelet count in the blood of patients with lumbago and sciatica. Anesthesia, essays and researches 2018; 12: 855. 